\title{
Focal cryotherapy for prostate cancer: a contemporary literature review
}

\author{
Srinath Kotamarti, Thomas J. Polascik \\ Division of Urologic Surgery, Duke Cancer Institute, Durham, NC, USA \\ Contributions: (I) Conception and design: Both authors; (II) Administrative support: Both authors; (III) Provision of study materials or patients: \\ Both authors; (IV) Collection and assembly of data: S Kotamarti; (V) Data analysis and interpretation: Both authors; (VI) Manuscript writing: Both \\ authors; (VII) Final approval of manuscript: Both authors. \\ Correspondence to: Thomas J. Polascik, MD, FACS. Division of Urology, Duke Cancer Institute, Durham, NC 27710, USA. \\ Email: Thomas.polascik@duke.edu.
}

\begin{abstract}
Objective: To perform a comprehensive review of the contemporary literature regarding both functional and oncologic outcomes after primary focal cryotherapy for prostate cancer (PCa), providing these results as a foundation for discussing recent developments in the realm of focal therapy.

Background: Traditional treatments for $\mathrm{PCa}$ are often associated with debilitating functional side effects for patients. Due to advances in imaging and biopsy strategies, focal ablative therapies recently have garnered much interest and offer an alternative primary treatment for PCa patients with localized disease. Focal cryoablation utilizes heat extraction from tissues to generate an iceball and cause tissue destruction while sparing uninvolved prostatic regions. Optimized patient selection and postoperative management continue to be areas of interest and study as the field continues to develop.

Methods: A search was performed of the PubMed and Embase databases to identify articles pertaining to primary focal PCa cryoablation since our group's last comprehensive review in 2016.

Conclusions: Primary focal cryoablation for PCa offers optimized functional outcomes and a favorable adverse event profile. True evaluation of oncologic outcomes is hampered by lack of long-term follow-up and highly variable clinical endpoints across these studies. Nonetheless, outcomes appear adequate in the shortto medium-term time frame. Utilization of focal cryoablation is expected to grow with continued refinement of patient selection and management options in cases of treatment failure.
\end{abstract}

Keywords: Prostate cancer (PCa); focal therapy; cryoablation; image-targeted therapy; outcomes

Submitted Sep 23, 2021. Accepted for publication Dec 23, 2021. Published online Jan 10, 2022.

doi: $10.21037 / \mathrm{atm}-21-5033$

View this article at: https://dx.doi.org/10.21037/atm-21-5033

\section{Introduction}

The second most common cancer in men, prostate cancer (PCa) is confined to the prostate gland as localized disease in $90 \%$ of men at diagnosis (1). Such patients requiring treatment have traditionally been offered either extirpative resection or whole gland radiotherapy, with either option offering adequate oncologic outcome $(2,3)$. Unfortunately, such treatments are not uncommonly associated with unintended damage to surrounding structures such as the urinary sphincter, pelvic floor, and neurovascular bundles that can negatively impact a man's urinary and sexual function $(4,5)$. Increased patient intolerance of these side effects has been fueled in recent years from heightened awareness related to unlimited internet-accessible information (3). To decrease patient burden from treatment, there has been an impetus to develop alternative treatment approaches for $\mathrm{PCa}$ with an emphasis on maximizing genitourinary functional outcomes while not compromising the oncologic outcome.

In recent years, investigations into partial prostate ablation gained attention after subtotal treatment demonstrated effectiveness in several other cancers, 
Page 2 of 14

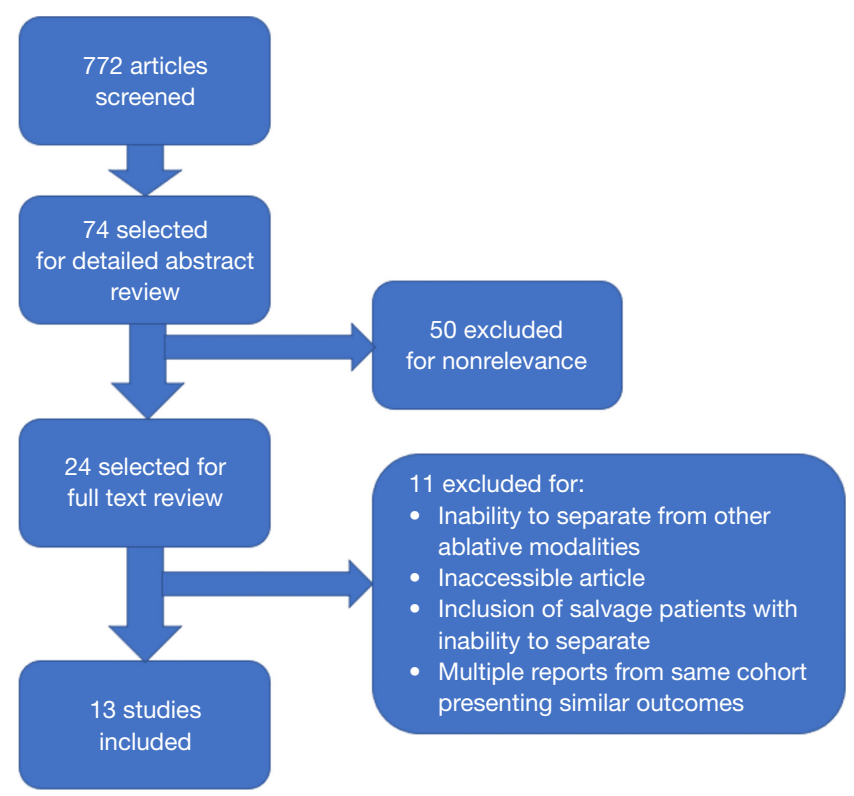

Figure 1 Review search protocol.

including renal, breast and lung (6-8). Improvements in imaging and diagnostic methods such as multiparametric magnetic resonance imaging (mpMRI) and targeted tissue biopsy have supported the implementation of focal treatment for appropriate candidates with clinically localized PCa (9). Studies including the PIVOT trial have also demonstrated the option to defer active treatment for lower risk disease (10). Thus, identification of a specific focus of clinically significant disease allows for targeted therapy while sparing uninvolved tissues, minimizing deleterious collateral effects to structures associated with sexual and urinary function (11). Even if untreated prostatic tissue harbors low risk disease, it may be surveilled and subsequently treated as necessary (10).

A thermal ablative technique, cryoablation causes destructive effects to intended target tissue via extraction of heat (12). It has a long history as an accepted ablative whole gland therapy for $\mathrm{PCa}$ and was first introduced as an alternative management for those patients unsuitable for primary means of treatment (12). Cryoablation has also undergone continued technologic development with improvement of utilized devices and associated imaging (11). Implemented as an option for focal PCa treatment, cryotherapy continues to be studied with several aspects including ideal patient selection and optimal postoperative management still being defined (11). In 2016, our group provided the last comprehensive dedicated review for $\mathrm{PCa}$ focal cryoablation, to our knowledge (11). We sought to review the contemporary literature since then for primary focal cryotherapy and provide context for these studies as the field continues to evolve. We present the following article in accordance with the Narrative Review reporting checklist (available at https://atm.amegroups.com/article/ view/10.21037/atm-21-5033/rc).

\section{Methods}

Our group previously published a review on localized PCa primary focal cryoablation in 2016, commenting on associated oncologic and functional outcomes (11). To build on the prior findings and provide a comprehensive review of more recent distinct studies, a systematic search of the PubMed and Embase databases was performed to identify reports of primary focal cryotherapy for PCa since the time of the prior review. Combinations of the following terms were utilized to perform the search: 'cryotherapy' OR ‘cryoablation' OR 'cryosurgery' OR 'partial ablation' OR 'image guided therapy' AND 'focal' AND 'prostate'. Figure 1 details the review protocol performed for this study. Studies including either oncologic or functional outcomes or both were selected. Full text versions of studies were favored over abstracts. Studies with multiple comparative arms including focal cryoablation were acceptable as long as focal cryotherapy-specific results were able to be isolated. Studies discussing salvage focal cryotherapy were excluded. In the event of multiple reports from a particular cohort, the latest study was selected. However, if a group presented separate articles for oncologic and functional outcomes, both articles were included. Articles presenting focal cryotherapy as a single arm of a multi-arm study were included if outcomes specific to cryoablation were available.

\section{Results}

The search protocol yielded 13 studies that were identified for inclusion after thorough assessment (Figure 1) (13-25). Eight studies were single center series, while three were multicenter cohorts and two were derived from the Cryo On-Line Data (COLD) multi-center registry. All included reports discussed primary focal prostate cryoablation.

\section{Inclusion criteria}

Table 1 includes basic inclusion criteria for the presented studies. The most recent included study's publication date 
Table 1 Inclusion, selection, ablation type, and follow-up protocols

\begin{tabular}{|c|c|c|c|c|c|c|}
\hline Study & Year & $\mathrm{N}$ & Criteria for inclusion & Diagnostic workup & Ablation type & Follow-up protocol \\
\hline $\begin{array}{l}\text { Elshafei } \\
\text { et al. (15) }\end{array}$ & 2018 & 829 & Localized disease & Not recorded & "Partial" & Not recorded \\
\hline $\begin{array}{l}\text { Kongnyuy } \\
\text { et al. (16) }\end{array}$ & 2018 & 104 & $\begin{array}{l}\text { Unilateral positive cores } \\
<\text { GGG4. Occasional } \\
\text { patients with unilateral } \\
\text { > GGG3 }\end{array}$ & Not recorded & Hemiablation & $\begin{array}{l}\text { Every } 3 \text { months for a year, } \\
\text { every } 6 \text { months thereafter for } \\
\text { PSA and digital rectal exams }\end{array}$ \\
\hline $\begin{array}{l}\text { Werneburg } \\
\text { et al. (17) }\end{array}$ & 2018 & 88 & $\begin{array}{l}\text { PSA }<10 \text {, unilateral } \\
\text { disease, lack of MRI ECE }\end{array}$ & Not recorded & Hemiablation & PSA at 3-month intervals \\
\hline $\begin{array}{l}\text { Bakavicius } \\
\text { et al. (19) }\end{array}$ & 2019 & 126 & Localized disease & $\begin{array}{l}\text { Systematic and targeted } \\
\text { transperineal biopsies }\end{array}$ & $\begin{array}{l}\text { Treatment of specific } \\
\text { area of the prostate } \\
\text { with a } 10 \mathrm{~mm} \text { safety } \\
\text { margin }\end{array}$ & Not recorded \\
\hline $\begin{array}{l}\text { Shah } \\
\text { et al. (20) }\end{array}$ & 2019 & 122 & $\begin{array}{l}\text { GGG2 or } 3 \text {, or high } \\
\text { volume GGG1 }\end{array}$ & $\begin{array}{l}\text { Transperineal mapping } \\
\text { or systematic }+ \\
\text { targeted biopsy or } \\
\text { systematic biopsy with } \\
\text { concordant MRI }\end{array}$ & $\begin{array}{l}\text { Unilateral anterior, } \\
\text { bilateral anterior, } \\
\text { bilateral posterior }\end{array}$ & $\begin{array}{l}\text { PSA testing } 3 \text { to } 6 \text { monthly } \\
\text { in first year and } 6 \text { months } \\
\text { thereafter. MRI at } 12 \text { months. } \\
\text { Biopsy performed when } \\
\text { recurrence was suspected }\end{array}$ \\
\hline $\begin{array}{l}\text { Gregg } \\
\text { et al. (23) }\end{array}$ & 2021 & 23 & $\begin{array}{l}\text { PSA } \leq 10,<50 \% \text { cores } \\
\text { positive, } \leq 50 \% \text { tumor } \\
\text { core length, GGG1-2 }\end{array}$ & $\begin{array}{l}\text { Confirmatory systematic } \\
\text { biopsy using robotic } \\
\text { assistance }\end{array}$ & Anterior hockey stick & $\begin{array}{l}3,6,12,18,24 \text { and } 36 \text { months } \\
\text { time points (exam, PSA, quality } \\
\text { of life measures) }\end{array}$ \\
\hline $\begin{array}{l}\text { Tan } \\
\text { et al. (24) }\end{array}$ & 2021 & 71 & $\begin{array}{l}\text { Individualized partial } \\
\text { gland ablation }\end{array}$ & $\begin{array}{l}\text { Fusion biopsy or 3-D } \\
\text { template mapping } \\
\text { biopsy }\end{array}$ & $\begin{array}{l}\text { Targeted, } \\
\text { hemiablation, subtotal } \\
\text { (hockey stick) }\end{array}$ & $\begin{array}{l}\text { Every } 6 \text { months for } 5 \text { years (PSA } \\
\text { and exam). MRI: } 3-6,12-24 \\
\text { months, and at } 5 \text { years. Biopsy } \\
\text { if PSA >0.5 ng/mL }\end{array}$ \\
\hline $\begin{array}{l}\text { Marra } \\
\text { et al. (25) }\end{array}$ & 2021 & 121 & Low/intermediate risk & $\begin{array}{l}\text { Systematic or saturation } \\
\text { or MRI targeted biopsy }\end{array}$ & $\begin{array}{l}\text { Lesional, quadrant, } \\
\text { hemiablation }\end{array}$ & $\begin{array}{l}\text { PSA every } 3 \text { months for the } 1 \text { st } \\
\text { year, then every } 6 \text { months. MRI: } \\
3-12 \text { months. Biopsy at } 1 \text { year }\end{array}$ \\
\hline
\end{tabular}

PSA, prostate specific antigen; GGG, Gleason grade group; MRI, magnetic resonance imaging; ECE, extracapsular extension; 3-D, 3-dimensional. 
was $4 / 2021$. Inclusion criteria amongst the studies varied, with 4 of 13 studies simply incorporating localized or unilateral localized disease, while the nine other studies mentioned parameters including variations of prostate specific antigen (PSA), mpMRI findings, or biopsy Gleason grade group (GGG). Eleven studies analyzed oncologic outcomes, seven studies analyzed functional outcomes, and six presented results for both. Ten studies were retrospective in nature, while three were prospective. Overall, eight studies $(61.5 \%)$ explained their pre-intervention diagnostic workup, with most reports utilizing either 3-dimensional (3-D) mapping biopsy or mpMRI fusion-targeted biopsy with systematic core sampling. Regarding the prospective studies, Inoue et al. (18) included patients with biopsy proven localized GGG3 PCa from MR fusion targeted biopsy using 3-D mapping technology; clinically significant $\mathrm{PCa}$ (csPCa) was not allowed to be detected on systematic biopsy. Wysock et al. (22) included only those patients with biopsy proven GGG $<4$ using the Artemis ${ }^{\circledR}$ (Eigen, Grass Valley, CA, USA) biopsy platform, without extraprostatic extension identified on mpMRI, and no GGG1 core length $>5 \mathrm{~mm}$ on the contralateral side of the prostate. In the last prospective study, Gregg et al. (23) included patients with $<50 \%$ of cores positive from a particular side of the gland, PSA $\leq 10 \mathrm{ng} / \mathrm{mL}$, no greater than $50 \%$ core length, only GGG1 or 2, and contralateral GGG1 $\leq 2 \mathrm{~mm}$ if present. Because mpMRI was not standard practice for their group at the time of the study, entry biopsies were performed in a systematic fashion only followed by a confirmatory biopsy in eligible patients with either the TargetScan Transrectal Ultrasound System (Envisioneering Medical Technologies, St. Louis, MO, USA) or the Artemis System (Eigen) (23) (Table 1).

\section{Demographics and basic clinical parameters}

The total number of patients included from all studies was 2,062, comprised of 995 patients from the COLD registry, 111 from prospective studies, and 956 from retrospective articles. The smallest cohort was that of Inoue et al. (18) with 5 patients and the largest was reported from the COLD registry from Elshafei et al. (15) (829 patients). Mean/median age and PSA from the cohorts ranged from 64 to 72 years and 3.9 to $10.8 \mathrm{ng} / \mathrm{mL}$, respectively (Table 2). Patient stratification according to D'Amico risk category when available or GGG are presented in Table 2. Seven $(53.8 \%)$ studies included high risk patients with a range of $1.4 \%$ to $28.7 \% \geq$ GGG4 across the cohorts. Of 8 studies that presented D'Amico risk stratification, five cohorts were predominantly intermediate risk while three featured mostly low risk patients.

\section{Focal technique}

Cryoablation pattern of ablation was described as either hemiablation-only (4 reports), targeted-only (1), anterior hockey stick-only (1), or a mix of these approaches (4). Three series did not have the approach described, including the two reports presenting data from the COLD registry, which does not offer this information (Table 1).

In all studies, cryoneedles were placed and the procedure was monitored under real-time transrectal ultrasound (US). Every study described the utilization of at least two freezethaw cycles with intralesional temperature targeted to a minimum of $-40{ }^{\circ} \mathrm{C}$. For those articles suggesting more than two cycles, Wysock et al. (22) stated utilization of a minimum of two freeze-thaw cycles, and Inoue et al. (18) described using two to three cycles with a median target intralesional temperature of $-51{ }^{\circ} \mathrm{C}$. A total of 8 of 13 $(61.5 \%)$ articles mentioned using thermocouples and 7 mentioned utilizing a urethral warmer catheter (53.8\%). Notably, the COLD registry does not report details of the focal therapy technique employed.

\section{Follow-up protocols}

Follow-up protocols were described in nine $(69.2 \%)$ of the included studies. All nine articles reported follow-up every 3-6 months for basic outcome measures i.e., physical exam including a digital rectal exam, PSA, and quality of life assessment. Five studies (38.5\%) included mpMRI as part of the post-operative protocol starting at 3-12 months postprocedure $(20-22,24,25)$. Four studies utilized mandatory biopsy as part of the protocol (21-23,25), with other cohorts performing a "for cause" biopsy if suspicion for recurrence arose. Biopsy technique, when mentioned, included sampling of both the treated and non-treated prostate (Table 1).

\section{Oncologic outcomes}

Eleven (84.6\%) studies specifically analyzed oncologic outcomes, which are presented in Table 3. Mean/median follow-up ranged from 6 to 85 months. Rate of postprocedural PSA decline was reported by two studies, with both Inoue et al. and Wysock et al. $(18,22)$ demonstrating 
Table 2 Preoperative clinical characteristics

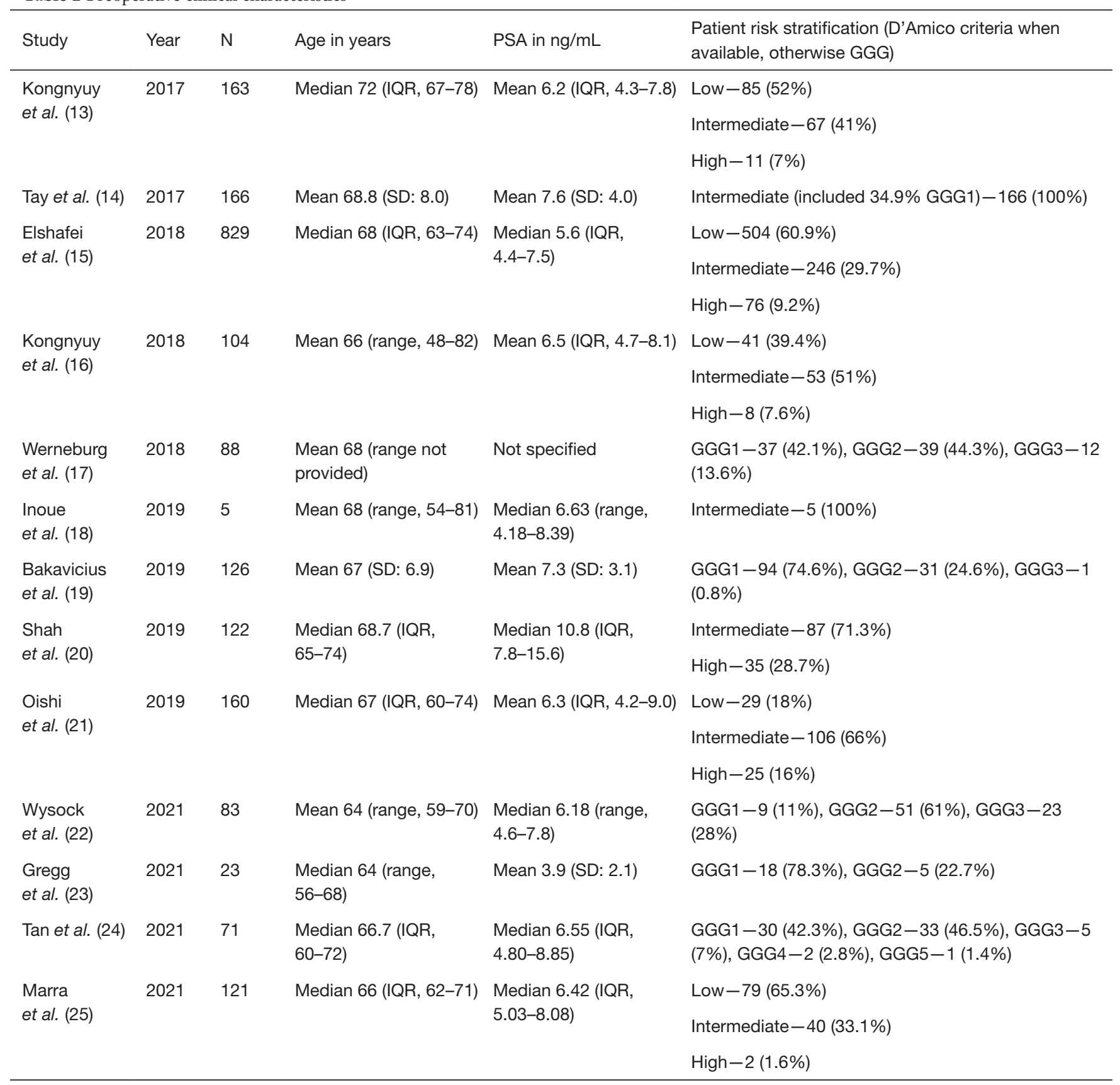

PSA, prostate specific antigen; GGG, Gleason grade group; IQR, interquartile range; SD, standard deviation.

median decline in PSA by approximately $71 \%$ at 6 months. The same studies commented on mpMRI findings postoperatively, with Inoue et al. (18) describing zero persistent lesions that were treated on mpMRI at 612 months, while Wysock et al. (22) demonstrated mpMRI to have a poor area under the curve (AUC) of 0.554 to predict subsequent biopsy in-field persistence. Biochemical failure was reported in five studies, with three using the Phoenix criteria, one using both Phoenix and Astro criteria, and one using both Phoenix and Stuttgart criteria. Utilizing Phoenix criteria, one study reported a biochemical recurrence-free survival (BCRFS) of $83.2 \%$ at a median of 


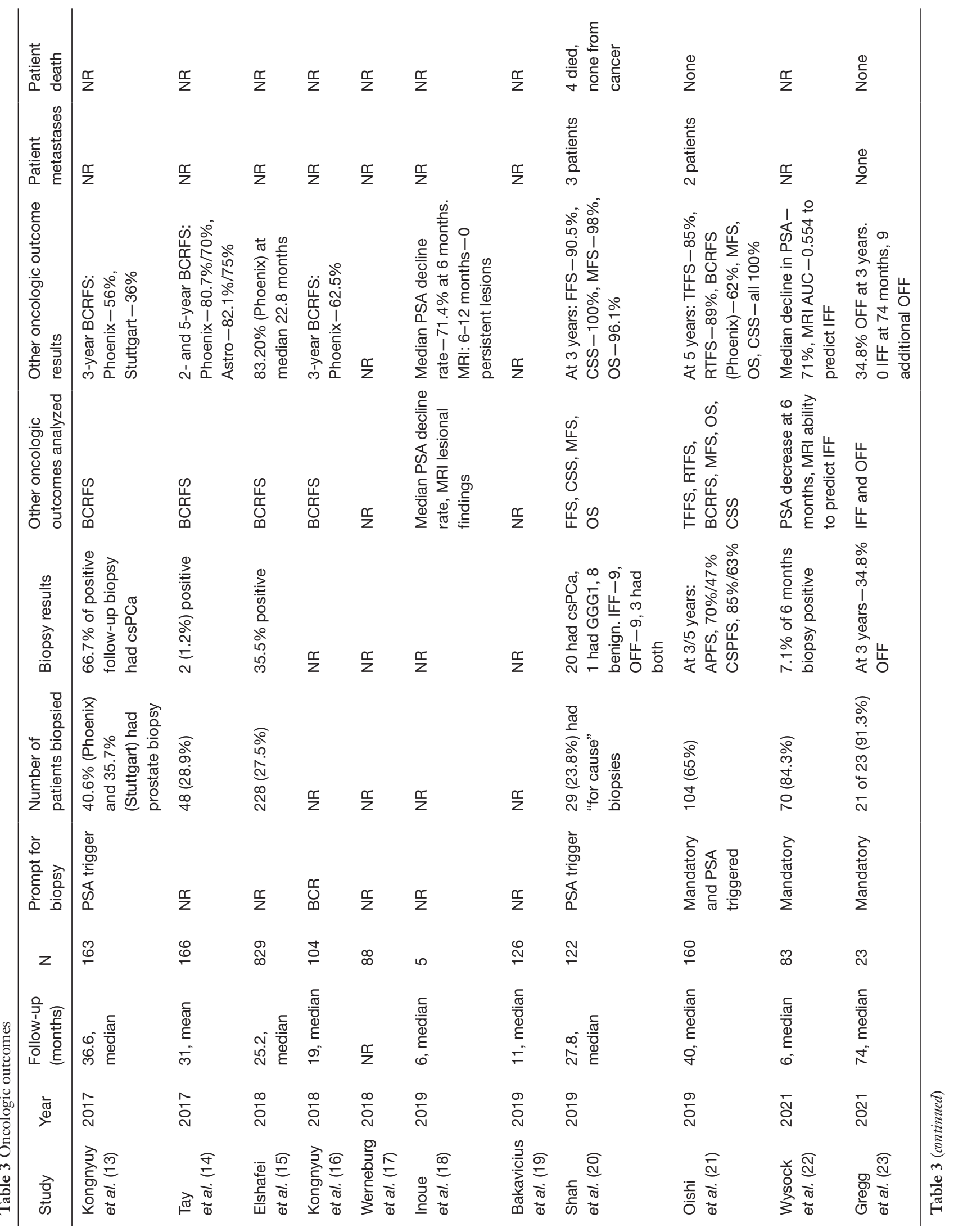




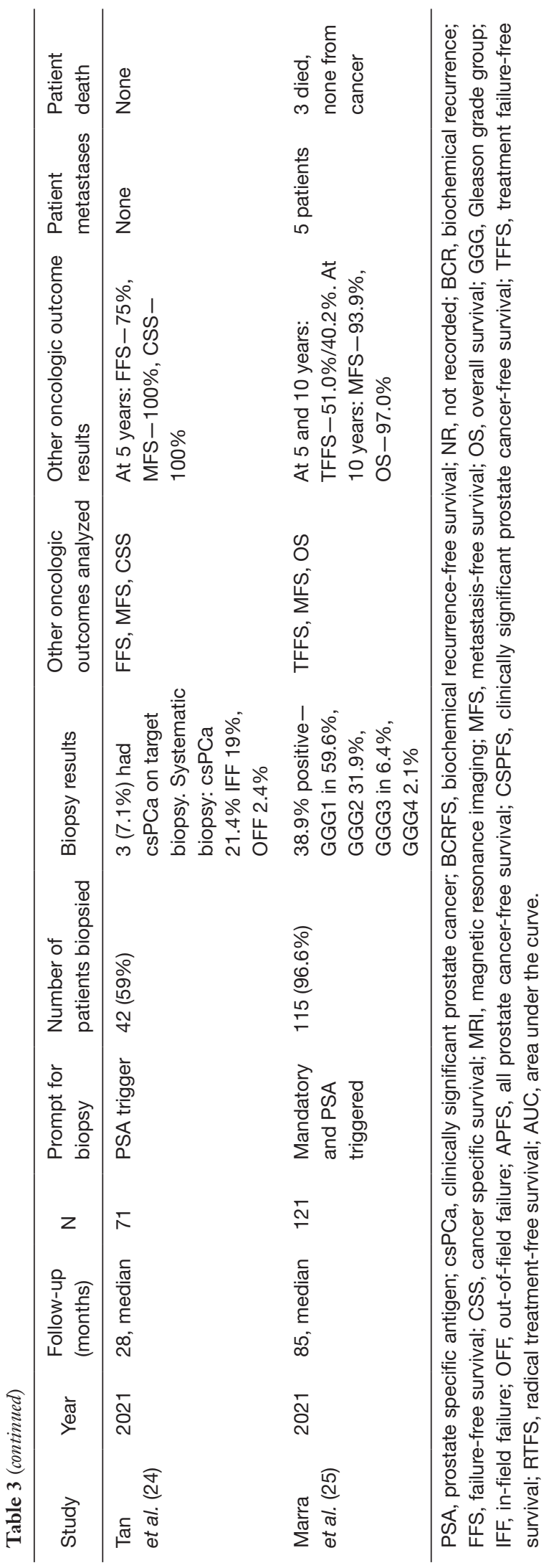

22.8 months (15), two studies quoted 3-year BCRFS from $56-62.5 \%(13,16)$, and two articles described 5 -year rates from $62-70 \%(14,21)$.

Nine $(69.2 \%)$ studies reported follow-up biopsy data, with $23.8-96.6 \%$ of patients undergoing post-cryoablation biopsy. Reported findings were highly variable, including positive biopsy rates, in-field (IFF) vs. out-of-field (OFF) failure rates, and rates of finding csPCa. Only four (30.8\%) studies had a mandatory biopsy as part of a follow-up protocol, all with a varied approach. Oishi et al. (21) used systematic sextant biopsy with image-targeted sampling of suspicious areas at 12 months and described 5 -year all PCa-free survival and csPCa-free survival to be $47 \%$ and $63 \%$, respectively. Wysock et al. (22) obtained four cores within the ablation zone and six systematic cores beyond the ablation zone at 6 months, finding $7.1 \%$ of their cohort were positive for PCa at 6-month biopsy. Gregg and colleagues implemented a 6 -month 12 core biopsy template directed towards the medial and lateral aspects of sextant prostate regions and saw zero IFF and $34.8 \%$ OFF at 3 years (23). Marra et al. (25) performed a 12-month "standard control biopsy" without further specification and demonstrated a $38.9 \%$ positive biopsy rate, with $40.4 \%$ returning with $\geq$ GGG2; $34.6 \%$ of recurrences were IFF, $25.3 \%$ were OFF, and $36 \%$ were both IFF and OFF.

Salvage therapy for treatment failure was reported in five studies $(38.5 \%)$, with few studies distinguishing whether further treatment was for IFF or OFF. Marra et al. (25) mentioned 54 (44.6\%) patients having salvage therapies, with $14.8 \%$ having redo focal cryoablation, $63 \%$ undergoing whole gland therapy such as radical prostatectomy (RP) or radiation, and $22.2 \%$ initiating androgen deprivation systemic therapy. Five- and 10-year radical treatment-free survival (RTFS) were $70.5 \%$ and $65 \%$, respectively (25). In their study, Gregg et al. (23) commented on two patients requiring repeat cryoablation at three years for $\mathrm{OFF}$, and two patients requiring treatment (1 radiation, 1 recryoablation) for further development of OFF at 74 months follow-up. Tan et al. (24) reported IFF in eight (19\%) patients and OFF in one patient, with five overall recurrences treated with repeated partial cryoablation (four of which subsequently had nadir less than $1 \mathrm{ng} / \mathrm{dL}$ ) and the rest undergoing either external beam radiotherapy (EBRT) or RP. In their cohort, Shah et al. (20) reported treatment failure-free survival to be $83.2 \%$, with 21 cases $(17.2 \%)$ of salvage: eight cases of repeat focal cryoablation, five RP, four radiation, and four cases of systematic therapy. Lastly, Oishi et al. (21) did not report specific salvage case numbers, 
however they did present a 5 -year RTFS of $89 \%$ in their cohort of 160 patients.

Only five $(38.5 \%)$ studies commented on metastasis and overall survival (OS). Within these studies, $10(2.0 \%)$ total patients developed metastases and seven $(1.4 \%)$ patients died (none from PCa). When reported, metastasisfree survival (MFS), cancer-specific survival (CSS), and OS ranged from $93.9-100 \%, 100 \%$, and $96.1-100 \%$, respectively (20,21,23-25).

\section{Functional outcomes and complications}

Table 4 presents data on complications and functional outcomes from the reviewed articles. In total, eight (61.5\%) studies analyzed adverse events and seven reported on functional sequelae post-prostate focal cryoablation. Posttreatment urinary continence rates ranges were described as $95.1-100 \%$ by $3-12$ months using definitions of EPIC score, "no leak", or "no pad use". Defined by various criteria, including IIEF score and more subjective measures such as "ability to penetrate", potency rates following focal cryosurgery when presented ranged from $46.8-83.8 \%$. Regarding notable complications, urinary retention rates were recorded at $0-9 \%$ post-focal cryoablation and rectourethral fistula was seen in up to $0.8 \%$ of patients across all cohorts. Other reported possible adverse events included urinary tract infection (mentioned in three studies with a maximum rate of $9 \%)(19,20,25)$, hematuria (mentioned in one study with rate of $5 \%$ ) (25), urethral sloughing (reported in one study with a rate of $3.2 \%$ ) (19), penoscrotal edema (discussed in two articles with a maximum rate of $9.8 \%)(19,20)$, stricture (mentioned in one study with rate of $0.8 \%$ ) (19), and osteomyelitis (mentioned in one study with rate of $0.8 \%$ ) (20). In their comprehensive review of perioperative adverse events, Bakavicius et al. (19) further reported rare, isolated cases of dysuria, hematospermia, renal colic, pain, and an instance of an allergic reaction. Three articles reported stratified complications using the ClavienDindo criteria, reporting high-grade ( $\geq$ Clavien 3 ) in six patients $(2.3 \%)$ out of a cumulative total of 266 across those studies $(20,23,25)$.

\section{Discussion}

First developed over 50 years ago, cryoablation employs the rapid freezing and thawing of intended target tissues currently using argon gas (12). Temperature lowering in the intended target to a minimum of $-40{ }^{\circ} \mathrm{C}$ promotes lethal iceball formation resulting in denaturation of proteins and destruction of intracellular components, as well as extracellular ice crystal formation and a hyperosmotic extracellular environment that establishes a trans-cellular membrane concentration gradient (26). The resulting fluid shift into the intracellular space causes cells to distend and burst (26). This mechanism of prostate cell apoptosis is further augmented by deleterious effects to blood supply and the immune response related to iceball formation $(26,27)$. Early initiatives implementing cryoablation into the PCa treatment paradigm focused on whole gland therapy, demonstrating adequate patient outcomes as well as a potential salvage therapy after radiation therapy failure $(28,29)$. However, recent advances in imaging and diagnostics including mpMRI, fusion targeting, and 3-D mapping biopsy have supported the growth of focal therapy as an emerging alternative to whole gland $\mathrm{PCa}$ treatments in select cases (9).

Review of relevant articles from the past five years confirms the findings of our previous review that primary focal cryoablation for localized disease is well tolerated with overall minimal impact on urinary and sexual function (11). Complication rates mentioned in eight studies were all low, and high grade Clavien $\geq 3$ complications did not surpass $4 \%$ in any study $(20,23,25)$. Urinary retention was the most encountered adverse event and is likely related to reactive edema. Three studies mentioned time until catheter removal (range of 1-10 days), with two of these also reporting retention rates $(19,22,23)$. Between those two studies, early post-cryotherapy retention occurred in 11 total patients, for a cumulative rate of $7.4 \%(19,23)$. Risk of retention can potentially be mitigated by increasing the time until postoperative trial of void; at Duke University, our protocol is maintenance of postoperative catheter for two weeks, obviating most of the early transient retention while providing sufficient time for the edema to resolve. With regards to continence, excellent rates were demonstrated in all reviewed studies, with six studies claiming 95.1-100\% urinary control occurring as soon as 3 months posttreatment. However, all six articles utilized non-validated outcome measures including "no leak" or "no pad use" as clinical thresholds. One study did include assessment of urinary continence via Expanded Prostate Cancer Index Composite (EPIC) scores, quoting an initial reduction followed an improvement within 12 months (17). Sexual functional outcomes were also heterogeneously defined and reported. Notably, Tay et al., Tan et al., and Gregg et al. reported the lowest outcomes of all studies, quoting 
Table 4 Complications/functional outcomes

\begin{tabular}{|c|c|c|c|c|c|c|}
\hline Study & Year & Complications & $\begin{array}{l}\text { Definition of } \\
\text { continence }\end{array}$ & $\begin{array}{l}\text { Reported } \\
\text { continence outcome }\end{array}$ & $\begin{array}{l}\text { Definition of } \\
\text { potency }\end{array}$ & $\begin{array}{l}\text { Reported potency } \\
\text { outcome }\end{array}$ \\
\hline $\begin{array}{l}\text { Kongnyuy } \\
\text { et al. (13) }\end{array}$ & 2017 & NR & NR & NR & NR & NR \\
\hline $\begin{array}{l}\text { Tay } \\
\text { et al. (14) }\end{array}$ & 2017 & Retention $6.6 \%$, fistula $0 \%$ & No leak & $95.1 \%$ at 12 months & $\begin{array}{l}\text { Ability to have } \\
\text { intercourse }\end{array}$ & $46.8 \%$ \\
\hline $\begin{array}{l}\text { Kongnyuy } \\
\text { et al. (16) }\end{array}$ & 2018 & NR & NR & NR & NR & NR \\
\hline $\begin{array}{l}\text { Werneburg } \\
\text { et al. (17) }\end{array}$ & 2018 & NR & EPIC & $\begin{array}{l}\text { Initial reduction then } \\
\text { rises by } 12 \text { months }\end{array}$ & IIEF score & $\begin{array}{l}\text { Lower early IIEF scores } \\
\text { but rapid improvement } \\
\text { by postoperative year } 2\end{array}$ \\
\hline $\begin{array}{l}\text { Bakavicius } \\
\text { et al. (19) }\end{array}$ & 2019 & $\begin{array}{l}\text { Retention } 7.1 \% \text {, UTI } 3.2 \% \text {, } \\
\text { urethral sloughing }(3.2 \%) \text {, } \\
\text { penoscrotal edema }(3.2 \%) \text {, } \\
\text { penoscrotal hematoma }(1.6 \%) \text {, } \\
\text { perineal abscess }(1.6 \%) \text {, } \\
\text { hypotension }(1.6 \%) \text {, fistula } 0.8 \% \text {, } \\
\text { stricture } 0.8 \% \text {, dysuria }(0.8 \%) \text {, } \\
\text { hematospermia }(0.8 \%) \text {, renal } \\
\text { colic }(0.8 \%) \text {, pain }(0.8 \%) \text {, allergic } \\
\text { reaction }(0.8 \%) \text {, acute kidney } \\
\text { injury }(0 \%)\end{array}$ & NR & NR & NR & NR \\
\hline $\begin{array}{l}\text { Wysock } \\
\text { et al. (22) }\end{array}$ & 2021 & NR & NR & NR & NR & NR \\
\hline $\begin{array}{l}\text { Gregg } \\
\text { et al. (23) }\end{array}$ & 2021 & $\begin{array}{l}2(9 \%) \text { grade } 2 \text { complications for } \\
\text { retention, } 1 \text { patient ( } 4 \% \text { ) had a } \\
\text { Clavien } 3 \text { complication (placement } \\
\text { of suprapubic catheter) }\end{array}$ & No pad use & $100 \%$ by 6 months & IIEF score & $\begin{array}{l}\text { Intercourse satisfaction } \\
\text { decreased from median } \\
\text { of } 13 \text { to } 8.5 \text { at } 6 \text { months }\end{array}$ \\
\hline $\begin{array}{l}\text { Tan } \\
\text { et al. (24) }\end{array}$ & 2021 & No rectal fistula & No pad use & $100 \%$ by 3 months & $\begin{array}{l}\text { Ability to achieve } \\
\text { an erection }\end{array}$ & $58 \%$ \\
\hline $\begin{array}{l}\text { Marra } \\
\text { et al. (25) }\end{array}$ & 2021 & $\begin{array}{l}\text { Retention } 8.3 \% \text {, UTI } 6.6 \% \text {, } \\
\text { hematuria } 5 \% \text {, fistula } 0.8 \% \text {, } \\
\text { urethral stenosis } 0.8 \% \text {, urethral } \\
\text { sloughing } 0 \%, \geq \text { Clavien } 3 \\
\text { complication in } 3 \text { patients }(2.4 \%)\end{array}$ & No pad use & $96.00 \%$ & IIEF score & $\begin{array}{l}\text { Median IIEF-5 } 14.5 \\
\text { (baseline 10) }\end{array}$ \\
\hline
\end{tabular}

NR, not recorded; EPIC, Expanded Prostate Cancer Index Composite; IIEF, International Index of Erectile Function; UTI, urinary tract infection. 
post-treatment potency as $46.8 \%, 58 \%$, and decreased International Index of Erectile Function (IIEF) score to 8.5 at 6 months, respectively $(14,23,24)$. The heterogeneous ablation patterns of included cohorts prevent making any conclusions regarding association of more extensive ablation with lower postoperative sexual function. A potential meaningful clinical outcome for future studies incorporating validated patient-reported outcome measures (PROM) is a return to baseline function, considering preoperative functional scores (30). Other authors have also reported using stratified functional scores (mild, moderate, and severe categories) and considering "significant" changes in scores $[3$ point change in International Prostate Symptom Score (IPSS) score, and 4 point change in Sexual Health Inventory for Men (SHIM) score in 6 months] $(31,32)$.

In 2015, the International Consensus of Urologic Disease (ICUD) convened an international expert panel to standardize outcome measures after focal therapy to provide consistency in reporting (33). Despite this, oncologic results from contemporary focal cryoablation reports often are confounded by heterogeneity with regards to preoperative risk stratification and lack of adherence to standard definitions of outcome measures for persistence, recurrence, and progression. In this review, at least two risk groups were included in nine of the 11 studies that offered preoperative biopsy pathology and $61.5 \%$ of cohorts included high risk patients, possibly contributing to the variation in certain results. Intuitively, different ablation patterns should have differing amounts of residual PSAsecreting prostate tissue remaining, making standardized biochemical definitions challenging (34). Failure after focal cryoablation can be divided into IFF and OFF, with the former signifying inadequate treatment and the latter signifying a "selection failure", especially if identified within the first 12-18 months (35). Management can be additionally stratified based on degree of disease, as some authors further define IFF as significant volume $(\geq 0.2 \mathrm{cc}$ or $\geq 7 \mathrm{~mm}$ diameter) of GGG2 within the treated area based on pathological data from the International Society of Urologic Pathology (ISUP) (36). Additionally, GGG1 tumors can generally be surveilled without immediate intervention (35). While some have suggested mandatory biopsy within 12 months to assess efficacy of the procedure, only 4 of 13 included studies featured mandatory re-biopsy, with most implementing a "for cause" biopsy based on a PSA trigger in consideration of biochemical recurrence (BCR) (37). BCR definitions also varied, with Phoenix (5 studies), Stuttgart (1 study), and Astro criteria (1 study) all represented. One study commented on the possible role of mpMRI to monitor these patients but featured a poor AUC of only 0.554 to predict IFF based on mpMRIs beginning at 6 months postoperatively (22); the finding reaffirms that mpMRI alone is insufficient to detect recurrence and periodic histologic sampling is still necessary (36).

Looking beyond initial treatment, further debate has centered on management options once suspicion for failure or BCR is confirmed with biopsy-proven recurrence. For csPCa identified as IFF, options include repeat targeted ablative treatment with the same or different energy, or whole gland approaches such as total ablation, RP, or radiotherapy $(35,38)$. On the other hand, OFF may be de novo lesions or disease missed at initial evaluation due to issue with sampling or invisibility on mpMRI (35). While these latter patients can be candidates for further targeted ablation, challenges of targeting MRI-invisible lesions may shift these patients towards whole gland management strategies (35). Further controversy exists regarding whether repeat focal therapy offers acceptable oncologic outcome compared to whole gland approaches however, this is likely due to patient selection factors (39). One advantage of ablative techniques is the ability to repeat the procedure in cases of treatment failure (35). One of the studies included in this review allowed for up to one further session of cryotherapy as part of the initial focal therapy intervention (20), with four other studies reporting use of repeated focal ablative intervention for treatment failure (21,23-25). Regarding more aggressive whole gland salvage approaches, one recent study quoted progression-free survival after salvage RP and radiation post-focal therapy failure to be $80.4 \%$ and $100 \%$ at 3 years, respectively (40). Another study of 82 patients undergoing RP after FT failure demonstrated only a $36 \%$ progression-free survival at 3 years but did describe a 12 -month continence rate of $83 \%$ and minimal perioperative comorbidity (41). In general, the current level of evidence regarding management for FT failure is low and limited to retrospective series (38).

PCa oncologic outcomes are ideally evaluated at least 10-15 years after treatment due to the long natural history of the disease (11). Both the treated and untreated areas need to be continually assessed radiographically and histologically. As focal cryoablation is still considered a developing technique, few cohorts have matured enough to provide such long-term outcomes (36). Nonetheless, reviewed studies providing oncologic results did highlight a $2 \%$ cumulative rate of patients developing metastases. While the overall review cohort featured mean/median follow- 
up of 6-85 months, two of the included papers featured longer term follow-up of 74 (23) and 85 months (25), with both examining treatment failure rates. Both studies featured high compliance with mandatory post-procedural biopsy and reported similar outcomes. Gregg et al. (23) reported no IFF and $34.8 \%$ OFF at three years with no IFF and nine subsequent OFF at 74 months (all GGG1). With even longer follow-up at 85 months, Marra et al. (25) reported a $38.9 \%$ positive biopsy rate and a 10 -year treatment failure-free survival of $40.2 \%$. For reference, the longest follow-up reported in our prior review in 2016 was that of Lian et al. (42) (63 months), in which those authors presented 41 patients with $7(17.1 \%)$ positive biopsies (2 IFF and 5 OFF, all GGG2) (38). Increasing to the ideal level of follow-up will allow focal cryotherapy cohorts to adequately assess key oncologic outcomes such as CSS and OS. These outcomes have been previously reported with whole gland cryoablation, with one example study demonstrating $87 \%$ CSS and $56.6 \%$ OS at 10 years in mostly high-risk patients (43).

The current review features studies with highly-varied approaches to biopsy strategy for patient selection, including only three cohorts incorporating 3-D template mapping biopsies and one utilizing a confirmatory systematic biopsy $(19,20,23,24)$. Indeed, such a heterogeneous approach is also evidenced in the literature, including usage of conventional systematic biopsy, saturation biopsy, fusion targeted biopsy, and 3-D template mapping biopsy. As such, there is a need to optimize and standardize how patients are selected for focal cryotherapy. Prior research has demonstrated that extended systematic biopsy compared to the classic sextant format improves diagnostic accuracy from $49 \%$ to $59 \%$ and improves detection of unilateral PCa (44). Various innovative approaches have also been investigated with regards to mpMRI-targeted biopsy. Aminsharifi et al. (45) previously demonstrated the utility of employing targeted biopsy with only a sextant systematic biopsy as a method of reducing overall number of biopsy cores through limiting random systematic biopsy cores, with any cancer and csPCa detected at $74.4 \%$ and $39.5 \%$, respectively, in active surveillance patients. Furthering the investigation into targeted biopsy technique, Tracy et al. (46) demonstrated incremental benefit in the utilization of an increased number of targeted biopsy cores, with $52 \%$ detection of csPCa at fifth lesional biopsy core compared to $26 \%$ for the first biopsy core. While laborious and requiring anesthesia, 3 -D template mapping biopsy with $5 \mathrm{~mm}$ sampling offers perhaps the most precise 3 -D representation of the location, volume and extent of disease, corresponding with a high rate of upgrading of disease after a previous TRUS biopsy to as high as $46 \%(9,47,48)$. Performed in a similar lithotomy position to transperineal approaches to focal therapy, this 3-D biopsy platform offers a fixed set of reproducible coordinates that translates well from biopsy to cryoablation (48).

Patient selection for focal cryoablation has and will also continue to be aided by developments with prostate imaging (49). US, universally used in a transrectal fashion for real-time imaging when performing cryoablation, has seen several recent developments. Contrast-enhanced US, better suited to detect regions of increased vascularity, was demonstrated to have improved cancer detection rates of $75 \%$ on targeted biopsy vs. $48.2 \%$ with standard transrectal US (50). Further combined with real-time elastography, contrast-enhanced US has demonstrated $89.7 \%$ cancer detection on targeted biopsy. mpMRI has had an ever-increasing role due to the ability to identify potential lesions, facilitate targeted biopsy and monitor treatment changes post-procedure. Currently performed at 1.5 or 3 Tesla, there have been investigations into the potential utility of an ultra-high magnetic field strength of 7 Tesla. Vos et al. (51) demonstrated satisfactory-togood overall image quality on T2-weighted imaging at 7 Tesla without an endorectal coil and the ability to identify csPCa lesions in patients with biopsy-proven lesions in the peripheral and transition zones. The authors surmised that increased special resolution with 7 Tesla MRI may enable new functional imaging techniques such as spectroscopic imaging of low-concentration metabolites (51). The utility of prostate specific membrane antigen positron emission tomography (PSMA-PET) to identify and locate tumor foci within the prostate has also been recently investigated, showing a slightly higher specificity (95\% vs. 94\%) and positive predictive value $(85 \%$ vs. $81 \%)$ compared to mpMRI to identify tumor foci on whole-mount histopathology (52). Nonetheless, the authors stated neither PSMA-PET nor mpMRI can currently replace prostate biopsy as a significant proportion of cancers are potentially underestimated and missed by both imaging modalities (52).

This review of contemporary primary focal cryoablation studies over the last five years demonstrates the tolerability and efficacy of the procedure to minimize detrimental functional outcomes in these patients. Recent advances in the field have resulted in efforts to expand indications for focal cryoablation. Evidenced by the high proportion of intermediate and high risk patients featured by studies 
included in this review, focal cryoablation is increasingly being investigated as an alternative treatment for higher risk disease. Further comparative research is required to assess the potential role of focal cryoablation to adequately eradicate higher-risk tumor cell clones (34). Focal cryoablation has also been preliminarily examined as a salvage treatment option post radiotherapy, with early reports demonstrating encouraging potency rates and similar 2-year oncologic outcomes compared to salvage total cryoablation (53). At this time, such endeavors should be considered developmental due to the lack of consistent long-term and high quality data.

\section{Conclusions}

Focal cryoablation in recent years has continued to demonstrate promising functional outcomes and adequate short-to-intermediate term oncologic outcomes. The current level of available data is primarily low and retrospective in nature, highlighting the need for further investigations. Research is needed to elucidate the optimal means to monitor these patients post-procedure and consider the best salvage option in cases of failure. With furthering of technologic advancements and research efforts, it is reasonable to expect continued improvement of patient selection and outcomes, as well as for the sustained expansion of potential indications.

\section{Acknowledgments}

Funding: None.

\section{Footnote}

Reporting Checklist: The authors have completed the Narrative Review reporting checklist. Available at https:// atm.amegroups.com/article/view/10.21037/atm-21-5033/rc

Conflicts of Interest: Both authors have completed the ICMJE uniform disclosure form (available at https://atm. amegroups.com/article/view/10.21037/atm-21-5033/coif). TJP is serving as the President of Focal Therapy Society with no remuneration. The other author has no conflicts of interest to declare.

Ethical Statement: The authors are accountable for all aspects of the work in ensuring that questions related to the accuracy or integrity of any part of the work are appropriately investigated and resolved.

Open Access Statement: This is an Open Access article distributed in accordance with the Creative Commons Attribution-NonCommercial-NoDerivs 4.0 International License (CC BY-NC-ND 4.0), which permits the noncommercial replication and distribution of the article with the strict proviso that no changes or edits are made and the original work is properly cited (including links to both the formal publication through the relevant DOI and the license). See: https://creativecommons.org/licenses/by-nc-nd/4.0/.

\section{References}

1. Buyyounouski MK, Choyke PL, McKenney JK, et al. Prostate cancer - major changes in the American Joint Committee on Cancer eighth edition cancer staging manual. CA Cancer J Clin 2017;67:245-53.

2. Koch MO, Gardner TA. Thermal-based treatment options for localized prostate cancer. Curr Treat Options Oncol 2005;6:379-87.

3. Beerlage HP. Alternative therapies for localized prostate cancer. Curr Urol Rep 2003;4:216-20.

4. Begg CB, Riedel ER, Bach PB, et al. Variations in morbidity after radical prostatectomy. N Engl J Med 2002;346:1138-44.

5. Benoit RM, Naslund MJ, Cohen JK. Complications after prostate brachytherapy in the Medicare population. Urology 2000;55:91-6.

6. Cao C, Chandrakumar D, Gupta S, et al. Could less be more?-A systematic review and meta-analysis of sublobar resections versus lobectomy for non-small cell lung cancer according to patient selection. Lung Cancer 2015;89:121-32.

7. Pierorazio PM, Johnson MH, Patel HD, et al. Management of Renal Masses and Localized Renal Cancer: Systematic Review and Meta-Analysis. J Urol 2016;196:989-99.

8. Veronesi U, Cascinelli N, Mariani L, et al. Twentyyear follow-up of a randomized study comparing breastconserving surgery with radical mastectomy for early breast cancer. N Engl J Med 2002;347:1227-32.

9. Barqawi AB, Stoimenova D, Krughoff K, et al. Targeted focal therapy for the management of organ confined prostate cancer. J Urol 2014;192:749-53.

10. Wilt TJ, Brawer MK, Jones KM, et al. Radical prostatectomy versus observation for localized prostate cancer. N Engl J Med 2012;367:203-13. 
11. Tay KJ, Polascik TJ. Focal Cryotherapy for Localized Prostate Cancer. Arch Esp Urol 2016;69:317-26.

12. Babaian RJ, Donnelly B, Bahn D, et al. Best practice statement on cryosurgery for the treatment of localized prostate cancer. J Urol 2008;180:1993-2004.

13. Kongnyuy M, Lipsky MJ, Islam S, et al. Predictors of biochemical recurrence after primary focal cryosurgery (hemiablation) for localized prostate cancer: A multiinstitutional analytic comparison of Phoenix and Stuttgart criteria. Urol Oncol 2017;35:530.e15-9.

14. Tay KJ, Polascik TJ, Elshafei A, et al. Propensity ScoreMatched Comparison of Partial to Whole-Gland Cryotherapy for Intermediate-Risk Prostate Cancer: An Analysis of the Cryo On-Line Data Registry Data. J Endourol 2017;31:564-71.

15. Elshafei A, Tay KJ, Kara O, et al. Associations Between Prostate Volume and Oncologic Outcomes in Men Undergoing Focal Cryoablation of the Prostate. Clin Genitourin Cancer 2018;16:e477-82.

16. Kongnyuy $M$, Islam $S, M b a h A K$, et al. PSA kinetics following primary focal cryotherapy (hemiablation) in organ-confined prostate cancer patients. World J Urol 2018;36:209-13.

17. Werneburg GT, Kongnyuy M, Halpern DM, et al. Effects of Focal vs Total Cryotherapy and Minimum Tumor Temperature on Patient-reported Quality of Life Compared With Active Surveillance in Patients With Prostate Cancer. Urology 2018;113:110-8.

18. Inoue $\mathrm{Y}$, Ushijima S, Shiraishi T, et al. Biochemical and magnetic resonance image response in targeted focal cryotherapy to ablate targeted biopsy-proven index lesion of prostate cancer. Int J Urol 2019;26:317-9.

19. Bakavicius A, Sanchez-Salas R, Muttin F, et al. Comprehensive Evaluation of Focal Therapy Complications in Prostate Cancer: A Standardized Methodology. J Endourol 2019;33:509-15.

20. Shah TT, Peters M, Eldred-Evans D, et al. EarlyMedium-Term Outcomes of Primary Focal Cryotherapy to Treat Nonmetastatic Clinically Significant Prostate Cancer from a Prospective Multicentre Registry. Eur Urol 2019;76:98-105.

21. Oishi M, Gill IS, Tafuri A, et al. Hemigland Cryoablation of Localized Low, Intermediate and High Risk Prostate Cancer: Oncologic and Functional Outcomes at 5 Years. J Urol 2019;202:1188-98.

22. Wysock JS, Becher E, Gogaj R, et al. Early oncological control following partial gland cryo-ablation: a prospective experience specifying reflex MRI guided biopsy of the ablation zone. Prostate Cancer Prostatic Dis 2021;24:114-9.

23. Gregg JR, Borregales LD, Choi H, et al. Prospective trial of regional (hockey-stick) prostate cryoablation: oncologic and quality of life outcomes. World J Urol 2021;39:3259-64.

24. Tan WP, Chang A, Sze C, et al. Oncological and Functional Outcomes of Patients Undergoing Individualized Partial Gland Cryoablation of the Prostate: A Single-Institution Experience. J Endourol 2021;35:1290-9.

25. Marra G, Soeterik T, Oreggia D, et al. Long-term Outcomes of Focal Cryotherapy for Low- to Intermediaterisk Prostate Cancer: Results and Matched Pair Analysis with Active Surveillance. Eur Urol Focus 2022;8:701-9.

26. Habibian DJ, Katz AE. Emerging minimally invasive procedures for focal treatment of organ-confined prostate cancer. Int J Hyperthermia 2016;32:795-800.

27. Baust JG, Gage AA, Bjerklund Johansen TE, et al. Mechanisms of cryoablation: clinical consequences on malignant tumors. Cryobiology 2014;68:1-11.

28. Polascik TJ, Mayes JM, Mouraviev V. From whole-gland to targeted cryoablation for the treatment of unilateral or focal prostate cancer. Oncology (Williston Park) 2008;22:900-6; discussion 906-7, 914.

29. Kimura M, Mouraviev V, Tsivian M, et al. Current salvage methods for recurrent prostate cancer after failure of primary radiotherapy. BJU Int 2010;105:191-201.

30. Shah TT, Peters M, Miah S, et al. Assessment of Return to Baseline Urinary and Sexual Function Following Primary Focal Cryotherapy for Nonmetastatic Prostate Cancer. Eur Urol Focus 2021;7:301-8.

31. Rosen RC, Allen KR, Ni X, et al. Minimal clinically important differences in the erectile function domain of the International Index of Erectile Function scale. Eur Urol 2011;60:1010-6.

32. Barry MJ, Cantor A, Roehrborn CG, et al. Relationships among participant international prostate symptom score, benign prostatic hyperplasia impact index changes and global ratings of change in a trial of phytotherapy in men with lower urinary tract symptoms. J Urol 2013;189:987-92.

33. Polascik TJ, Tay KJ, Ghai S, et al. Surveillance after prostate focal therapy. In: Sanchez-Salas S, Desai M. editors. Image-guided therapies for Prostate and Kidney Cancer. Montréal: Société Internationale d'Urologie (SIU), 2016.

34. van der Poel HG, van den Bergh RCN, Briers E, et al. 
Focal Therapy in Primary Localised Prostate Cancer: The European Association of Urology Position in 2018. Eur Urol 2018;74:84-91.

35. Lebastchi AH, George AK, Polascik TJ, et al. Standardized Nomenclature and Surveillance Methodologies After Focal Therapy and Partial Gland Ablation for Localized Prostate Cancer: An International Multidisciplinary Consensus. Eur Urol 2020;78:371-8.

36. Tay KJ, Amin MB, Ghai S, et al. Surveillance after prostate focal therapy. World J Urol 2019;37:397-407.

37. Scheltema MJ, Tay KJ, Postema AW, et al. Utilization of multiparametric prostate magnetic resonance imaging in clinical practice and focal therapy: report from a Delphi consensus project. World J Urol 2017;35:695-701.

38. Marra G, Valerio M, Emberton M, et al. Salvage Local Treatments After Focal Therapy for Prostate Cancer. Eur Urol Oncol 2019;2:526-38.

39. Mustafa M, Delacroix S, Ward JF, et al. The feasibility and safety of repeat cryosurgical ablation of localized prostate cancer. World J Surg Oncol 2015;13:340.

40. von Hardenberg J, Cash H, Koch D, et al. Triggers and oncologic outcome of salvage radical prostatectomy, salvage radiotherapy and active surveillance after focal therapy of prostate cancer. World J Urol 2021;39:3747-54.

41. Marconi L, Stonier T, Tourinho-Barbosa R, et al. Robotassisted Radical Prostatectomy After Focal Therapy: Oncological, Functional Outcomes and Predictors of Recurrence. Eur Urol 2019;76:27-30.

42. Lian H, Zhuang J, Yang R, et al. Focal cryoablation for unilateral low-intermediate-risk prostate cancer: 63-month mean follow-up results of 41 patients. Int Urol Nephrol 2016;48:85-90.

43. Cheetham P, Truesdale M, Chaudhury S, et al. Long-term cancer-specific and overall survival for men followed more than 10 years after primary and salvage cryoablation of the prostate. J Endourol 2010;24:1123-9.

44. Tsivian M, Kimura M, Sun L, et al. Predicting unilateral prostate cancer on routine diagnostic biopsy: sextant vs extended. BJU Int 2010;105:1089-92.

Cite this article as: Kotamarti S, Polascik TJ. Focal cryotherapy for prostate cancer: a contemporary literature review. Ann Transl Med 2023;11(1):26. doi: 10.21037/atm-215033
45. Aminsharifi A, Gupta RT, Tsivian E, et al. Reduced Core Targeted (RCT) biopsy: Combining multiparametric magnetic resonance imaging - transrectal ultrasound fusion targeted biopsy with laterally-directed sextant biopsies An alternative template for prostate fusion biopsy. Eur J Radiol 2019;110:7-13.

46. Tracy CR, Flynn KJ, Sjoberg DD, et al. Optimizing MRI-targeted prostate biopsy: the diagnostic benefit of additional targeted biopsy cores. Urol Oncol 2021;39:193.e1-6.

47. Barqawi AB, Rove KO, Gholizadeh S, et al. The role of 3-dimensional mapping biopsy in decision making for treatment of apparent early stage prostate cancer. J Urol 2011;186:80-5.

48. Kanthabalan A, Emberton M, Ahmed HU. Biopsy strategies for selecting patients for focal therapy for prostate cancer. Curr Opin Urol 2014;24:209-17.

49. Ashrafi AN, Tafuri A, Cacciamani GE, et al. Focal therapy for prostate cancer: concepts and future directions. Curr Opin Urol 2018;28:536-43.

50. Zhao HX, Xia CX, Yin HX, et al. The value and limitations of contrast-enhanced transrectal ultrasonography for the detection of prostate cancer. Eur J Radiol 2013;82:e641-7.

51. Vos EK, Lagemaat MW, Barentsz JO, et al. Image quality and cancer visibility of T2-weighted magnetic resonance imaging of the prostate at 7 Tesla. Eur Radiol 2014;24:1950-8.

52. Rhee H, Thomas P, Shepherd B, et al. Prostate Specific Membrane Antigen Positron Emission Tomography May Improve the Diagnostic Accuracy of Multiparametric Magnetic Resonance Imaging in Localized Prostate Cancer. J Urol 2016;196:1261-7.

53. Tan WP, ElShafei A, Aminsharifi A, et al. Salvage Focal Cryotherapy Offers Similar Short-term Oncologic Control and Improved Urinary Function Compared With Salvage Whole Gland Cryotherapy for Radiation-resistant or Recurrent Prostate Cancer. Clin Genitourin Cancer 2020;18:e260-5. 